Available online on 15.04.2020 at http://jddtonline.info
(c) 2011-18, publisher and licensee JDDT, This is an Open Access article which permits
unrestricted non-commercial use, provided the original work is properly cited

Open Access

Research Article

\title{
Assessment of Medication Adherence Barriers in COPD Patients in A Secondary Care Teaching Hospital
}

\author{
Aneena Annu Philip, Manisha Mohanan*, Merine Shine, Sherin Sara Benny, Poornima Ashok \\ Department of pharmacy practice, KLE College of pharmacy, Bangalore-10, Karnataka, India
}

\begin{abstract}
Background: COPD is characterised by persistent airway obstruction in which better clinical outcome can be attained by appropriate management of disease. Adherence to COPD medication is poorly understood due to chronic nature of the disease. It is crucial to identify the barriers of non-adherence to build up and execute policies and interventions to upgrade medication adherence. Objective: To identify the predisposing barriers of medication adherence and to find the association between medication adherence and variables. Methods: A descriptive analytical study was conducted and data was collected from COPD outpatients. The Morisky Medication Adherence Scale was used to measure adherence and self-assessed questionnaire was employed to identify the predictors of poor adherence. Chi square test was carried out to find the relationship between medication adherence and variables such as age, gender, literacy, socioeconomic class, polypharmacy, del ivery device and climate. Results: A total of 403 patients were involved in the study where $68 \%$ reported lower adherence. The most common adherence barriers found were forgetfulness (88\%), intentional stoppage of medicines when symptoms improve (83\%) and negligence towards medication (82\%).A significant association was found between gender, literacy, socioeconomic class, polypharmacy, delivery device and climate. Conclusion Adherence to medication regimen in COPD patients is poor, even though it is a preventable and a treatable disease. Well-structured education, training, counseling is required to overcome medication adherence particularly among illiterate and low socioeconomic class patients. The combined interventions should be used such as video clips demonstrations of inhaler technique should be given.
\end{abstract}

Keywords: COPD, Morisky medication adherence scale, Chi square test.

Article Info: Received 02 Feb 2020; Review Completed 20 March 2020; Accepted 29 March 2020; Available online 15 April 2020

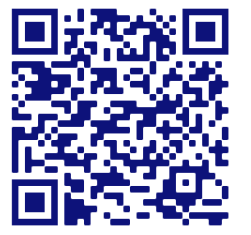

\section{Cite this article as:}

Philip AA, Mohanan M, Shine M, Benny SS, Ashok P, Assessment of Medication Adherence Barriers in COPD Patients in A Secondary Care Teaching Hospital, Journal of Drug Delivery and Therapeutics. 2020; 10(2-s):80-85 http://dx.doi.org/10.22270/jddt.v10i2-s.4013

Manisha Mohanan, Department of pharmacy practice, KLE College of pharmacy, Bangalore-10, Karnataka, India

\section{INTRODUCTION}

Chronic Obstructive Pulmonary Disease (COPD) characterizes an imperative general health challenge and is the main reason for morbidity and mortality all throughout the world. In 2012, a total of 6\% deaths were reported globally because of the disease. In coming years, COPD liability is projected to expand due to constant exposure to predisposing factors. As of now, it is the fourth driving reason for death in the world yet is anticipated to be the 3 rd prominent reason for death by 2020 .

In 2003, World Health Organization's (WHO) Adherence Project defines adherence as "the extent to which a person's behavior (taking medication, following a diet, and/or executing lifestyle changes) corresponds with agreed recommendations from a healthcare provider".(1) As per WHO, patients who were on long term treatment have shown $50 \%$ or less adherence. COPD patients exhibit remarkably poor adherence to treatment than asthmatic patients. (2)
Underuse, overuse, improper use are the three typical forms of medication non-adherence.

In order to implement newer policies and disease management strategies to enhance medication adherence and clinical outcomes, there needs a minimum recognition of medication adherence barriers. (3)

The intention of this study is to identify some of the essential perspectives influencing adherence to medication and to distinguish certain indicators of poor adherence in COPD patients. (2)

\section{METHODOLOGY}

A descriptive analytical study was carried out in the outpatient department of KCG hospital, from October 2018 to March 2019. Stable patients more than 40 years old and analysed as COPD as indicated by the Global Initiative for Chronic Obstructive Lung Disease (GOLD) criteria were consecutively incorporated into the research. Patients with 
psychiatric disorder and those who are not willing to participate were not included in the study. The total number of COPD patients participated in the study was 403. All participants handed out their written informed consent and the study was ratified by the Ethics Committee of KLECOP. A self -assessed questionnaire on adherence barriers in patients was carried out and validated with an indicated Cronbach's alpha of $0 .+74$. It comprises of 16 items in the questionnaire, depicting the determinants of medication non-adherence. Adherence was assessed using Morisky Medication Adherence Scale which is a 4 item questionnaire where the scoring pattern of 'Yes' $=0$ and ' $\mathrm{No}^{\prime}=1$ was used. The summary score of the MMAS ranges from 0 - 4, in which higher scores show more noteworthy adherence. Economic and sociologic conditions were measured using Kuppuswamy socioeconomic scale, holding the education and occupation of the head of the family which gives the socioeconomic status of the patients. Association between medication adherence and the variables were then analysed.

\section{RESULT}

Out of 403 patients participated in the study, there were more male patients (59\%) than females (41\%). The mean age of patients was 63.13 years and greater number of patients belonged to age group of $61-70$ years (36\%). In this study $64 \%$ of respondents were observed with cigarette smoking. The proportion of literate patients were significantly higher (67\%) compared to illiterate patients (33\%).Most were identified in the upper lower $(42.7 \%)$ socioeconomic class followed by lower middle $(25.5 \%)$ lower $(18.62 \%)$ and upper middle $(13 \%)$ socio economic class. Also 257(64\%) were administered with multiple medications. Furthermore, $47 \%$ of the population used inhalers, $32 \%$ used nebulizers while $21 \%$ were found to be using only oral medications.

Adherence pattern of 403 patients were measured using Morisky Green Levine Scale and it was found that 274 (68\%) were non adherent while $129(32 \%)$ were adherent to the prescribed treatment. According to self-reported questionnaire among 274 non-adherent patients, the most common cause of non-adherence found were forgetfulness $(88 \%)$ and intentional stoppage of medication use (83\%) when the symptoms improve. Other reasons include negligence towards medication (82\%), polypharmacy (56\%), lack of family support (53\%), delay of medication refill from pharmacy (48\%), refusal of medication use in public (42\%). Chi-square test was employed to analyse the association among adherence and variables where gender, literacy, socioeconomic status, polypharmacy, delivery device of inhaled medication and climate showed significant association. However there was no association found with age groups $(\mathrm{p}=0.860)$

\begin{tabular}{|c|c|c|c|c|c|c|}
\hline Variable & Total (n) & Adherent ( $\mathrm{n}=129)$ & $\%$ & Non-adherent (274) & $\%$ & p-value \\
\hline \multicolumn{7}{|l|}{ Age groups(years) } \\
\hline $40-50$ & 33 & 10 & 30 & 23 & 70 & \multirow{4}{*}{0.860} \\
\hline $51-60$ & 116 & 39 & 34 & 77 & 66 & \\
\hline $61-70$ & 147 & 49 & 33 & 98 & 67 & \\
\hline $71-80$ & 107 & 31 & 29 & 76 & 71 & \\
\hline \multicolumn{7}{|l|}{ GENDER } \\
\hline Male & 238 & 61 & 26 & 177 & 74 & \multirow[t]{2}{*}{0.001} \\
\hline Female & 165 & 68 & 41 & 97 & 59 & \\
\hline \multicolumn{7}{|l|}{ LITERACY } \\
\hline Literate & 269 & 109 & 41 & 160 & 59 & \multirow[t]{2}{*}{0.001} \\
\hline Illiterate & 134 & 20 & 15 & 114 & 85 & \\
\hline \multicolumn{7}{|l|}{ Socioeconomic classes } \\
\hline Lower & 75 & 13 & 17 & 62 & 83 & \multirow{4}{*}{0.001} \\
\hline Upper lower & 172 & 47 & 27 & 125 & 73 & \\
\hline Lower middle & 103 & 43 & 42 & 60 & 58 & \\
\hline Upper middle & 53 & 26 & 49 & 27 & 51 & \\
\hline \multicolumn{7}{|l|}{ Polypharmacy } \\
\hline Non-polypharmacy & 146 & 79 & 54 & 67 & 46 & 0.001 \\
\hline Polypharmacy & 257 & 50 & 19 & 207 & 81 & \\
\hline \multicolumn{7}{|l|}{ Delivery devices } \\
\hline Inhaler & 191 & 86 & 45 & 105 & 55 & \\
\hline Nebuliser & 127 & 24 & 19 & 103 & 81 & 0.001 \\
\hline No nebulisation or inhaler & 85 & 19 & 22 & 66 & 78 & \\
\hline
\end{tabular}




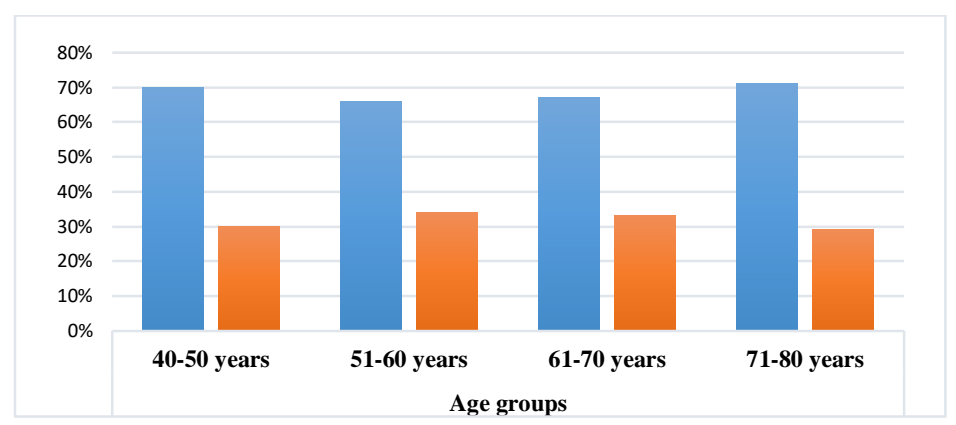

Fig 1: Adherence pattern among age group

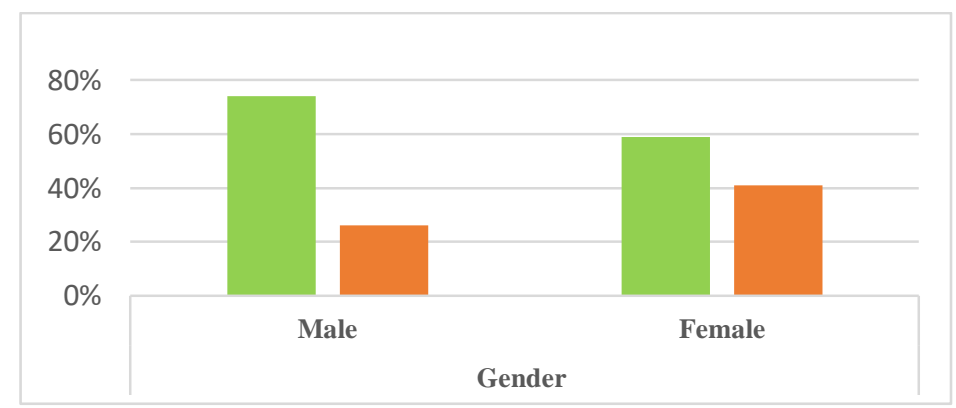

Fig 2: Adherence pattern among gender

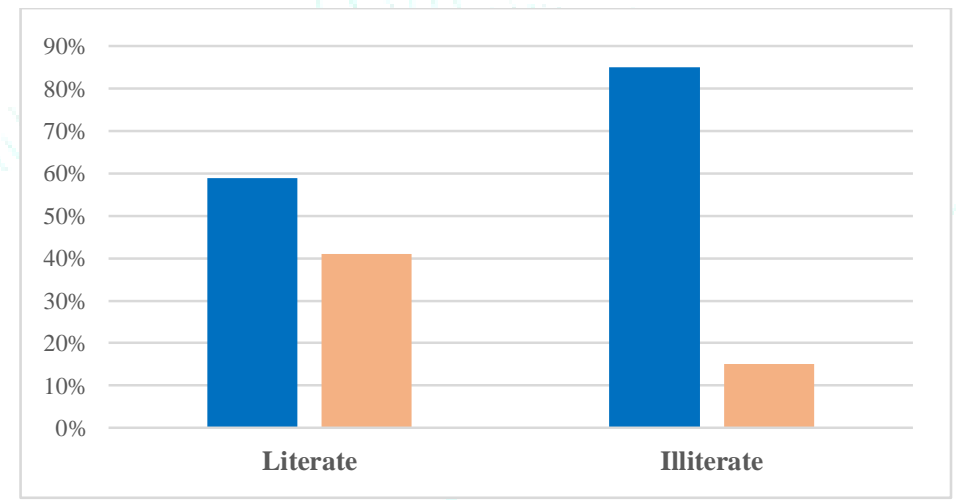

Fig 3: Adherence pattern among literate and illiterate patients

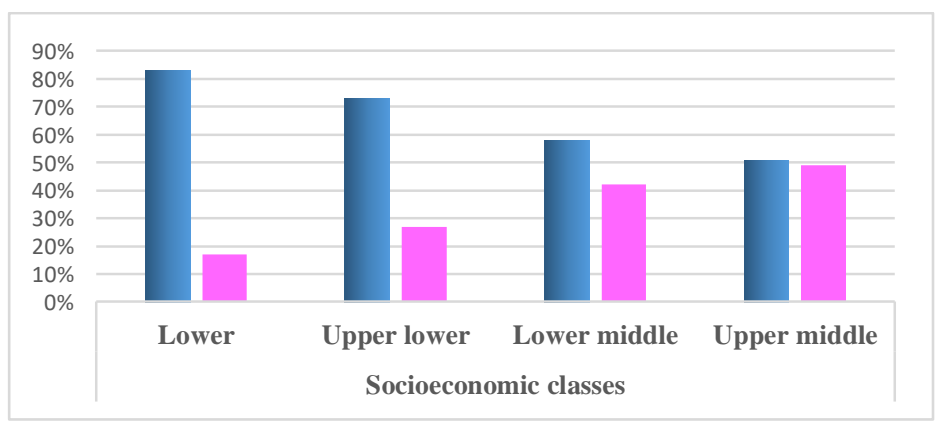

Fig 4: Adherence pattern among socioeconomic classes

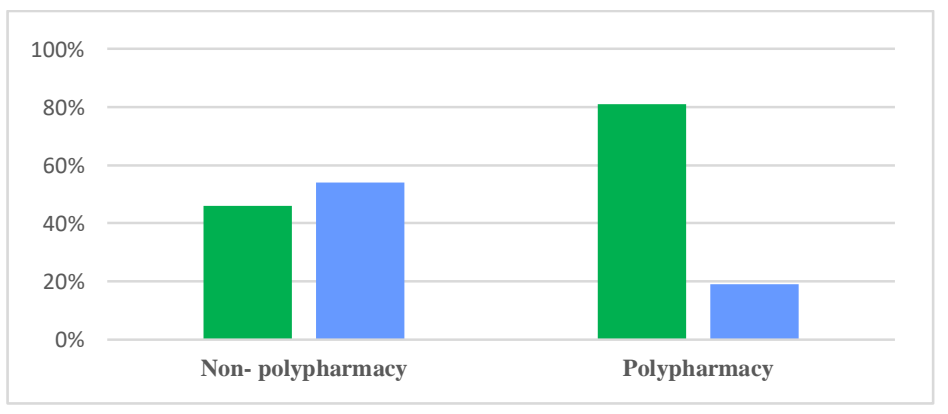

Fig 5: Adherence pattern among polypharmacy and non-polypharmacy patients 


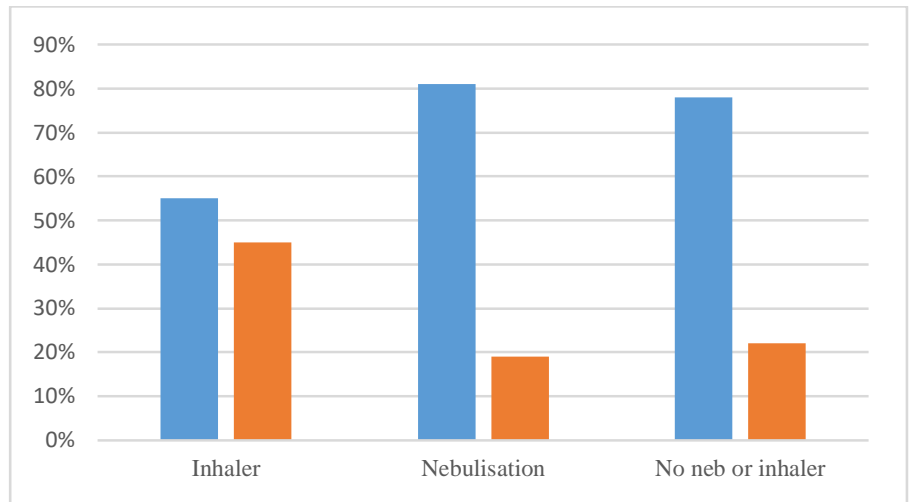

Fig 6: Adherence pattern of medication delivery devices

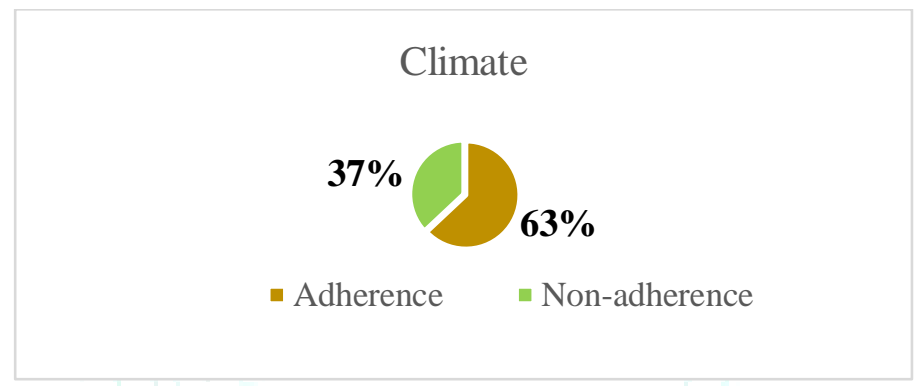

Fig 7: Adherence pattern in relation to climatic conditions.

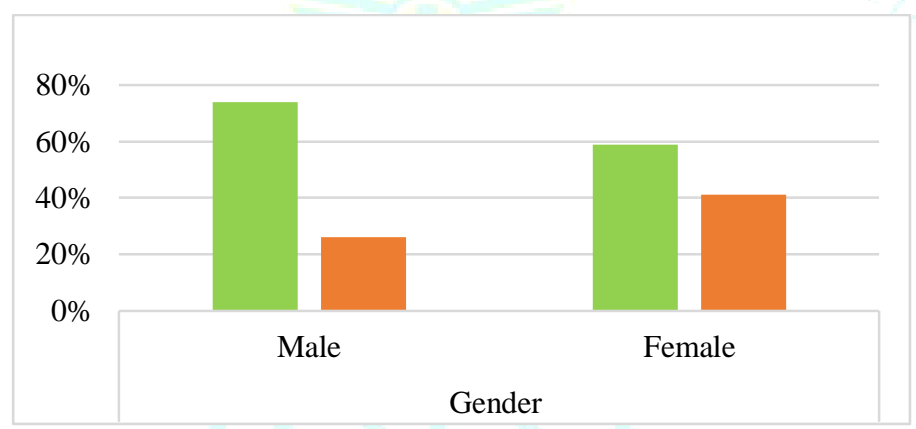

Fig 8: Adherence pattern among gender

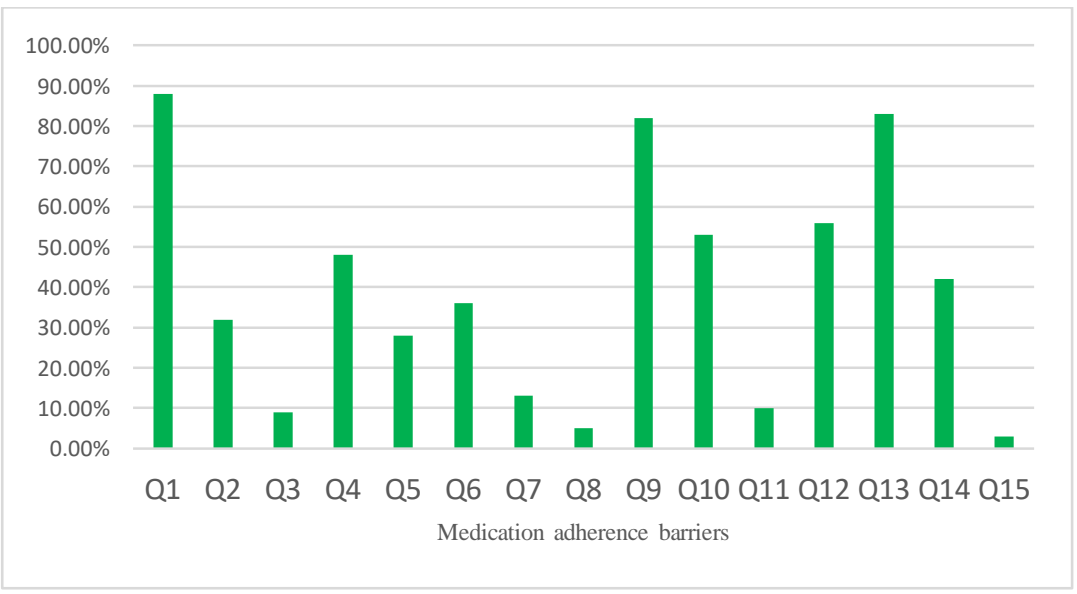

Fig 9: Percentage of medication adherence barriers 


\section{DISCUSSION}

Poor adherence to medications often results in increased frequency of exacerbations and mortality among COPD patients. (4) In this study with 403 patients, 32\% were reported adherence to COPD medications while 68\% reported non adherence which was inconsistent with the study by T Agh et al who reported $58.2 \%$ of adherence. (5) A significant association was found between adherence and variables such as gender, literacy, polypharmacy, socioeconomic status, delivery devices of inhaled medications and climate. A higher incidence of COPD was found in the age group of 60-70 years. According to WHO, the occurrence of COPD is common after the age of 40 years and increases proportionally with age increments (6) Among the considered age groups, non-adherence was greater in 70-80 years (71\%) which is arguably due to forgetfulness, cognitive impairments, complex treatment regimen, lack of family support, depression, strong sense of loss and feelings of hopelessness.(7)

Our study showed association between gender and adherence as similar to previous studies. $(8,9,10)$ Alcohol consumption, smoking, busy schedules, less concerns regarding disease and treatment influences medication taking behavior within men. This was in controversy with the findings of prior studies where female patients showed less adherence. Illiterate patients displayed less priority to self-care and being part of a minority group and having low income resulted in lesser ability to understand medical information and label instructions which lead to decreased adherence compared to literate patients. (11,12,13,14) Furthermore, our results suggests that socioeconomic status was significantly associated with adherence where lower socioeconomic group showed highest non adherence than other groups. In our study most patients were in the older population and required complex medications for various comorbid conditions which led to frustration and confusion and resulted in unintentional non adherence. However J Bourbeau illustrated that no significant relation was found between polypharmacy and medication adherence. (15)

The results suggests that $63 \%$ of patients were adherent only during winter when the symptoms hamper their daily functioning while $37 \%$ were adherent irrespective of seasonal variations. Nebulizers or inhalers were recommended to the patients according to the patient convenience. In this study $44 \%$ of patients were adherent to inhalers whereas only $19 \%$ were adherent to nebulizer. Within the given study facility, the availability of nebulizer were free of cost but the patients had to be present in person to avail this facility thus they became non-adherent as many had commuting difficulty and lack of family support. Individuals prescribed with inhalers, which are to be obtained from outside the hospital thus making them unaffordable to the study population. Moreover, patients who have their own inhalers fail to procure refill medications which make them equally non-adherent and inconsistent. Other plausible reasons for non-adherence to inhalers were side effects, forgetfulness and inappropriate inhaler use or less confidence in using inhalers.

Most frequently affecting factors of medication adherence were found to be forgetfulness and intentional stoppage of medications when symptoms improved which was consistent with the study by L Laforest et al , AS Gadkari et al A R Fugate et al and I H Galal et al $(16,17,18,19)$ Patients misinterpret the lack of clinical symptoms as a cure and go for episodic treatment forsaking regular medications hence they execute self-treatment and approaches despite the instructions given by the healthcare professionals. $(15,20)$ Other reasons found from the study were negligence towards medication where reasons behind it was lack of seriousness to illness or treatment, lack of self- worth, poor insight and laziness or lack of care. Subsequently another factor found for non-adherence was polypharmacy followed by lack of family support which influences their medication taking behavior. Other reasons found from the study were medication refill delay from pharmacy, refusal of medication use in public, feeling of no benefit from treatment, poor knowledge about medication burden of disease, beliefs like prayer or religious dogmas will help to cure disease, side effects (headache, insomnia and nasal congestion) misbeliefs regarding treatment, trust issues with health care system.

Our study is one of the few study to determine the influence of socioeconomic status on medication adherence. However the study had few limitations. The influence of cost of medication on adherence couldn't be studied as the study was conducted in a government hospital and medicines were freely dispensed from the pharmacy. Correspondingly the time period of the study was limited and medication taking behavior of the upper socioeconomic class could not be assessed from the study site as the patients belonging to this group consulting in our setting was low.

\section{CONCLUSION}

In our study, forgetfulness, intentional stoppage of medicines when symptoms improve, negligence to medication, polypharmacy and inadequate family support were reported as the important barriers of medication adherence among COPD patients. A significant association was correspondingly identified between medication compliance and following variables like gender, education, socioeconomic status, climate, polypharmacy, and delivery device of inhaled medications that influence the adherence to a greater extent. Our study was majorly concerned in recognizing the medication taking behavior of patients with low socioeconomic status where health care providers can play a vital role in helping them to overcome the adherence barriers. Low literacy patients can be benefitted by comprehensive counseling and training involving video clip instructions, writings and demonstrations which could be an effective method for enhancing health literacy. Education emphasizing on benefits of medication adherence and enabling the patients for proper inhaler use results in improved self -confidence and perception towards disease and treatment. Inhaler technique of patient's should also be checked by physicians during every follow up visits and their feedbacks should be recorded to enhance adherence. Simplified medication regimens with less frequent dosing must be recommended to reduce confusion and frustration in patients.

There is a need to develop and implement newer amendments as well as procedures in health care system by government bodies and organizations to enhance medication adherence along with counseling, education or training focusing on barriers.

\section{ACKNOWLEDGMENT}

Authors are highly thankful to the Head of the department and Principal, KLE College of pharmacy Bangalore for providing essential facilities to accomplish this research study. The authors are also sincerely thankful to the management and staff of KC general Hospital, Malleshwaram, Bangalore for allowing us to conduct this work. 


\section{CONFLICT OF INTEREST}

The authors declare no conflict of interest.

\section{ABBREVIATIONS}

COPD: Chronic Obstructive Pulmonary Disease; WHO: World Health Organization; GOLD: Global Initiative for Chronic Obstructive Lung Disease; MMAS: Morisky Medication Adherence Scale

\section{REFERENCES}

1) World Health Organisation. Adherence to long-term therapies: evidence for action

2) Restrepo RD, Alvarez MT, Wittnebel LD, Sorenson H, Wettstein $\mathrm{R}$, Vines $\mathrm{DL}$ et al. Medication adherence issues in patients treated for COPD. Int J COPD. 2008 Sep 3; (3):371-384

3) Kardas P, Lewek P, Matyjasczyk M. Determinants of patient adherence: a review of systematic reviews. Front Pharmacol. 2013 Jul 25;4:91

4) Toyama $T$, Kawayama $T$, Kinoshita $T$, Imamura $Y$, Yoshida $M$ ,Takahashi $\mathrm{M}$ et al. Differences in Adherence Barriers to Inhaled Medicines between Japanese Patients with Chronic Obstructive Pulmonary Disease and Asthma Evaluated using the "Adherence Starts with Knowledge 20" (ASK-20) Questionnaire. Internal Medicine 2019:0488-17

5) Agh T, Inotai A, Mezsaros A. Factors associated with medication adherence in patients with chronic obstructive pulmonary disease. Respiration. 2011; 82(4):328-34.

6) World Health Organisation (WHO). Chronic Obstructive Pulmonary Disease. Factsheet 315. http://www.who.int/mediacentre/factsheets/fs315/en/ (accessed 22September2015).

7) Roberts NJ, Ghiassi R, Patridge MR. Health literacy in COPD. International journal of chronic obstructive pulmonary disease. 2008 Dec; 3(4):499

8) Dias A, Pereira C, Monteiro MJ, Santos C. Patient's beliefs about medicines and adherence to medication in ischemic heart disease. Atencion primaria 2014 Nov 1; 46:101-6

9) Gelaw BK, Mohammed A, Tegegne GT, Defersha AD , Fromsa $\mathrm{M}$, Tadesse $\mathrm{E}$ et al. Non-adherence and contributing factors among ambulatory patients with antidiabetic medications in Adama Referral Hospital. Journal of diabetes research 2014; 2014.
10) Ross S, Walker A, Macleod MJ. Patient compliance in hypertension: role of illness perceptions and treatment beliefs. Journal of human hypertension. 2004 Sep; 18(9):607

11) Davis E, Marra C, Gamble JM, Farrell J, Lockyer J, FitzGerald JM et al.Effectiveness of a pharmacist-driven intervention in COPD (EPIC): study protocol for a randomized controlled trail. Trials. 2016 Dec; 17(1):502

12) Kokturk N, Polatil M, Oguzulgen IK, Saleemi S, Al Ghobain M, Khan J et al. Adherence to COPD treatement in Turkey and Saudi Arabia:results of the aDCare study. International journal of chronic obstructive pulmonary disease. 2018; 13;1377

13) Kale MS, Federman AD, Krauskopf K, Wolf M, O'Conor R, Martynenko $\mathrm{M}$ et al. The association of health literacy with illness and medication beliefs among patients with chronic obstructive pulmonary disease. PLoS One. 2015 Apr 27; 10(4):e0123937

14) Roberts NJ, Ghiassi R, Patridge MR. Health literacy in COPD. International journal of chronic obstructive pulmonary disease.2008 Dec;3(4):499

15) Bourbeau J, Barlett SJ. Patient adherence in COPD.Thorax. 2008 Sep 1; 63(9):831-8

16) Laforest L, Denis F, Van Gansea E, Ritleng C, Saussier C, Passante $\mathrm{N}$ et al. Correlates of adherence to respiratory drugs in COPD patients. Primary Care Respiratory Journal. 2010 Jan $21 ; 19(2): 148$

17) Gadkari AS, McHorney CA. Unintentional non-adherence to chronic prescription medications: how unintentional is it really? BMC health sevices research. 2012 Dec; 12(1):98.

18) Fugate AR, Kadam AM, Ganachari MS. Prospective Study of Medication Adherence Pattern in Chronic Obstructive Pulmonary Disease and Asthma Patient's in Tertiary Care teaching Hospital. Indian Journal of Pharmacy Practice. 2015 Apr; 8(2):79

19) Galal IH, Mohammad YM, Nada AA, Mohran YE. Medication adherence and treatment satisfaction in some Egyptian patients with chronic obstructive pulmonary disease and bronchial asthma. Egyptian Journal of Bronchology. 2018 Jan $1 ; 12(1): 33$

20) Apps LD, Harrison SL, Williams JE, Hudson N, Steiner M, Morgan MD et al. How do informal self-care strategies evolve among patients with chronic obstructive pulmonary disease managed in primary care? A qualitative study. International journal of chronic obstructive pulmonary disease. 2014; 9:257 